\title{
Saberes,
}

\section{Sujetos y}

Métodos de

\section{Enseñanza.}

Reflexiones sobre

la apropiación de la

Escuela Nueva en

Colombia

Rafael Rios Beltrán y Javier Sáenz Obregón (Editores)

Por: Steven Navarrete Cardona

Universidad Nacional de Colombia 
L a educación no ha sido simplemente un problema de métodos, estructura, didáctica y planes curriculares, sino también una cuestión política sobre ¿el cómo? y qué se debe impartir al interior de las aulas, donde a su vez todos los involucrados como el maestro y el educando no son simples marionetas de la estructura económica y educativa, sino sujetos que se empoderan, reflexionan, apropian y transforman los saberes y los métodos pedagógicos según el contexto. El libro que reseñamos en esta oportunidad resulta en un esfuerzo mancomunado entre la Universidad de Antioquia, la Universidad Nacional de Colombia y el Centro de Estudios Sociales (CES) y que presenta los resultados de dos proyectos de investigación realizado a tres bandas por el grupo de investigación interuniversitario Historia de la práctica pedagógica en Colombia, el de Formación y Antropología Pedagógica e Histórica y el de Pedagogía y practicas pedagógicas, GIPEPP. Y nos presentan desde una perspectiva genealógica la recepción del método pedagógico de la Escuela Nueva (Activa o escuela de los instintos como afirma Javier Sáenz) en la primera mitad de siglo XX en Colombia, desde sus formas primigenias de apropiación en el Gimnasio Moderno, pasando por su masificación en las escuelas públicas del país bajo la tutela de Agustín Nieto Caballero, hasta el declive de la misma tras la caída de la republica liberal y el posicionamiento de la restauración conservadora.

El libro está divido en 9 capítulos antecedidos por una presentación conjunta entre los editores que busca contextualizar al lector sobre algunos libros que ya han abordado la recepción de la Escuela Nueva en nuestro país, además de desagregar las tendencias mediante las cuales se dio el proceso de apropiación de las concepciones y prácticas de la Escuela Nueva que se puede resumir en cuatro ítems según los editores; a) Escuela Examinadora, que transformo las escuelas en laboratorio de experimentación b) escuela defensiva, la cual asumió las escuelas como espacio para construir una raza culta y civilizada, que privilegio las intervenciones de maestros y alumnos hacia la familia y la población pobre (Esta apuesta está promovida fue defendida por Rafael Bernal Jiménez sobrino de Miguel Jiménez López) c) la reforma de los métodos de enseñanza y d) Educación para la democracia (Beltrán, Sáenz, 2012, p. 10)

El primer capítulo nos presenta una novedosa e interesante visión sobre la idea que las elites y los organismos institucionales construyeron en la década del 30 del siglo pasado de los adolescentes tras la apropiación de dicha categoría de la psicología del desarrollo en el país y los avatares de la intensificación de las formas de gobierno sobre los adolescentes (Beltrán, Sáenz, 2012, p 18) tanto de los que pertenecían a la clase media y que estaban bajo el régimen del gobierno-saber en la escuela como de aquellos hijos de las clases populares que no ingresaban a la secundaria. (Beltrán, Sáenz, 2012, p 19) centrándose sobre los grandes esfuerzos que se hicieron por ejercer un mayor control sobre la dimensión sexual y las prácticas de medicalización y control que surgieron para predecir y normaliza el comportamiento de los mismos (Beltrán, Sáenz, 2012, p 28). El segundo capítulo analiza el papel que la educación física tubo para la Escuela Nueva, resaltando la prioridad sobre el papel de lo corpóreo y la experiencia en el proceso de la adquisición del saber, las excursiones y los paseos, entre otras.

El tercer capítulo nos presenta un balance sobre los métodos, procedimientos y textos de los cuales se echó mano para transmitir el conocimiento no solo de la Escuela Nueva (haciendo un especial énfasis en la apuesta de Decroly) sino también de la escuela tradicional, como el deletreo, el silabeo, y la Cartilla Objetiva de Cesar Baquero entre otros, (Beltrán, Sáenz, 2012, p 97) el método global e ideovisual entre otros, procurando una útil distinción entre método y procedimiento. (Beltrán, Sáenz, 2012, p 98)

El cuarto capítulo indaga la relación entre la enseñanza de las ciencias naturales en la primera mitad del siglo XX y su relación con la Escuela Nueva, centrándose en el análisis en las primeras apuestas pedagógicas que tenían lugar en las escuelas normales a través de las tesis de grado (Beltrán, Sáenz, 2012, p 139) El capítulo tiene como marco conceptual la definición de pedagogía de Olga lucia Zuluaga (que va a ser uno de los ejes de desarrollo de todos los autores del libro) proponiendo al final del capítulo un ejercicio comparativo y de revisión a algunas apuestas didácticas de revistas pedagógicas españolas de mitad del siglo XX con una apuesta contemporánea.

El quinto capítulo no solo resulta en un balance historiográfico y bibliográfico sobre el cómo y desde que tendencias de investigación se ha abordado la Escuela Nueva en Colombia, sino también en un una mirada introspectiva desde los maestros superando la visión determinista de simples reproductores del orden social y de los métodos que le el ministerio de instrucción pública les imponía y evidenciando diversos ejemplos sumamente interesantes que fueron desarrollados en las tesis de grado de la Escuela Normal superior de Medellín. Para realizar dicho balance historiográfico el autor ubica dos estudios pioneros el primero de ellos encabezado por Javier Sáenz Obregón, Oscar Saldarriaga y Armando Ospina, publicado con el título Mirara la infancia: pedagogía, moral y modernidad en Colombia 1903-1946. 
(Beltrán, Sáenz, 2012, p 167) Y el segundo la tesis doctoral de Martha Cecilia Herrera Modernización y Escuela Nueva en Colombia 1914-1951. (Beltrán, Sáenz, 2012, p 167). El capítulo sexto resulta en un complemento del anterior, pero este capítulo se va a centrar en analizar las implicaciones del concepto de apropiación para el análisis de las ciencias sociales, examinando el mismo desde una mirada arqueológica y genealógica (En términos de Foucault) lo que resulta en otro gran aporte y eje central del libro, no obstante tiene una base en la realidad material del proceso de apropiación debido a una perspectiva propia en base a una trayectoria cultural, religiosa y política en el país que influyo en la forma en que se aplicaron los métodos de la Escuela Nueva. Como por ejemplo puede citarse la ausencia de la educación conjunta para hombres y mujeres que estaba prevista en dicha corriente pedagógica entre otros diversos ejemplos que se pueden constatar en la historia de la educación.

El séptimo capítulo examina la confluencia de la Ley Uribe de 1903, de la Escuela Activa y de la resistencia Católica durante el inicio de la organización de los grandes proyectos educativos en las primeras tres décadas del siglo XX en Medellín. El autor plantea un ejercicio histórico interesante en cuanto busca evidenciar no solo la mezcla de los tres ejes que se describieron anteriormente no solo discursivamente sino también materialmente, ejercicio que servirá de contexto para el análisis del concepto de apropiación que traen los capítulos siguientes. También resalta los énfasis de esta forma peculiar del proceso educativo que combinaba rasgos de la escuela activa en su preferencia por lo práctico, por el método con algunos rasgos culturales que se han construido socialmente en la región antioqueña, como el trabajo duro y constante. (Beltrán, Sáenz, 2012, p 206).

El octavo capítulo indaga en la relación existente entre pedagogía y didáctica y proponiéndose darle al lector algunas herramientas para su distinción basándose en un análisis concreto sobre la literatura pedagógica de referencia en la Escuela Normal de Varones de Medellín.

El noveno capítulo, uno de los más interesantes como su título lo indica explora los usos pedagógicos contemporáneos del discurso Deweyano. El pensamiento del filósofo Norte Americano John Dewey ya ha sido abordado por Javier Sáenz en diversos libros, artículos y traducciones, donde se hace implícita la preocupación sobre la incomprensión del potencial de las implicaciones cognoscitivas, epistemológicas y didácticas de la obra de Dewey. En esta oportunidad el autor se centra en la apuesta de Dewey por el pluralismo pedagógico, la superación de la concepción adap- tativa y su apuesta por la actividad transformadora de los sujetos, su apuesta por la consideración del contexto o perspectiva contextual, su apuesta por un maestro crítico y autónomo, su ruptura con la visión dualista y hegemónica de su época que separaba a teoría de la práctica pedagógica. El capítulo cierra con un análisis sobre el pensamiento de Dewey frente a la relación contenido-método, niño-currículo e interés y esfuerzo. Apartados desarrollados cuidadosamente que evidencian el potencial de la obra de Dewey al aplicarla los procesos pedagógicos contemporáneos.

El libro resulta entonces en una excelente fuente para todos aquellos que quieran ahondar sobre la historia de las prácticas pedagógicas en nuestro país, sobresaliendo no solo por el abordaje interdisciplinar y riguroso que se le da al tema evaluado y al equipo que reúne, sino además por presentar diversas imágenes que ejemplifican el contenido del mismo pertenecientes al archivo fotográfico de la Escuela Normal Superior de Medellín junto a una creativa portada del libro construida con las imágenes del mismo archivo, algo muy poco convencional y sumado a la utilización del (hasta ahora poco explorado) archivo de la Escuela Normal Superior de Medellín, sumado a la nueva propuesta interpretativa de Javier Sáenz sobre el pensamiento de Dewey.

La lectura del libro despierta diversas preguntas entre ellas; ¿tiene alguna relación el pasado y el presente de la educación en nuestro país? ¿Vale la pena continuar escribiendo e investigando sobre la historia de la educación? Mi respuesta rotunda y sin vacilaciones es que sí, la situación educativa del país es resultado de un proceso histórico que tiene aún muchos avatares por indagar y descubrir solo pensando históricamente (en términos de Marc Bloch), es decir desde el presente, pensando el pasado podremos comprender el futuro de la educación en Colombia.

Steven Navarrete Cardona
Universidad Nacional de Colombia

\section{Bibliografia}

Beltrán Ríos Rafael, Sáenz Obregón Javier. Saberes, sujetos y métodos de enseñanza reflexiones sobre la apropiación de la Escuela Nueva en Colombia eds. Bogotá Universidad Nacional de Colombia. Estudios Sociales (CES) Universidad de Antioquia. Facultad de Educación 2012. p 333.

Bloch, Marc: Introducción a la historia; traducción de Pablo González Casanova y Max Aub. México Fondo de Cultura Económica. 2011.202 p. 